\title{
SUPERNUMERARY CHROMOSOMES AND CHIASMA DISTRIBUTION IN TRITICUM SPELTOIDES
}

\author{
Y. ZARCHI*, J. HILLEL† and G. SIMCHEN‡ \\ Deportment of Genetics, The Hebrew University, Jerusalem, Isroel
}

Received 5.xi.73

* Present address: Poultry Breeders Union of Israel, 12 Bialik Street, Tel Aviv, Israel.

$\dagger$ Present address: Faculty of Agriculture, The Hebrew University, Rehovot, Israel.

\section{SUMMARY}

\begin{abstract}
Supernumerary (B) chromosomes were found in two out of three population samples of Triticum speltoides from Turkey and further samples were studied from two Israeli populations previously reported to consist of a high frequency of B-carriers (Simchen et al., 1971). In the two Israeli populations, plants with $\mathrm{B}$ chromosomes have a lower frequency of terminal chiasmata and a higher frequency of interstitial chiasmata. This effect is proportional to the number of $B$ chromosomes per plant, which varies in one population between 0 and 8 and in the other between 0 and 3 . Evidence for selection against plants with a high number of $\mathrm{Bs}$ is presented.
\end{abstract}

\section{IntroduGtion}

SuPERnumerary (B) chromosomes were reported in two out of five populations of Triticum speltoides in Israel (Simchen et al., 1971). We have now analysed more extensive samples of these populations, as well as samples from three additional populations in Turkey. Two of the latter also contained supernumerary chromosomes. In the present study we examine the distribution of chiasmata in individuals carrying different numbers of $\mathrm{B}$ chromosomes, from 0 to 8 per individual. In the two Israeli populations, fewer terminal and more interstitial chiasmata can be found in B-carriers and the magnitude of this effect is linearly proportional to the number of B chromosomes. No such effect was observed in the Turkish populations.

\section{Materials AND Methods}

A description of populations 08 and 09 (in two locations in Israel, near Acre and Haifa, respectively) was given in our previous publications (e.g. Zarchi et al., 1972). Population 08 consisted mainly of plants of the ligustica type and population 09 contained almost solely speltoides-type plants (see Zohary and Imber 1963, for the relationship between these two morphs). In the summer of 1970 we collected new samples from populations 08 and 09. We also obtained samples from three additional populations in Turkey, collected by D. Zohary and G. Ladizinsky in 1970. Population 13 is located on the northwest outskirts of Gaziantep, 1100 metres above sea-level. The soil is of Terra Rossa calcerous type. Most plants are of speltoides morphology. Population 14 is located $10 \mathrm{~km}$ east of Adana, in an alluvial valley, approx. 70 metres above sea-level. Most plants are of ligustica morphology. Population 15 is located $5 \mathrm{~km}$ west of Urfa, 800 metres above sea-level, Terra Rossa slope, on a hard limestone. These were mainly speltoides plants.

$\ddagger$ Reprint requests to this author, 
Whole spikes were sampled, one from each plant, with 1 metre minimum distance between two adjacent plants. Between 50 and 100 spikes were thus obtained, of which 20-30 were randomly chosen for sowing. In the autumn of 1970 , the total seed from each spike were germinated in a separate petri dish. The germlings were transferred to small pots and after establishment were planted in our Jerusalem experimental field, which contained several thousand plants, all randomised. The plants chosen for the cytological examination of pollen mother cells (PMC) in 1971 were coded by their field number (which was not related to their origin). This sample contained up to 4 plants from a single original spike and the five populations were represented by 33-59 plants each, as shown in table 1 . In addition, we obtained in 1971 a sample of PMG from plants growing in the natural habitat of population 09 (28 plants, as indicated in table 1). Eleven additional plants are included in table 1 , which were among progeny of plants studied in previous years and in which we had other interests.

TABLE 1

Samples subject to the full cytological examination

\begin{tabular}{|c|c|c|c|c|c|c|c|c|c|c|c|}
\hline \multirow[b]{2}{*}{$\begin{array}{c}\text { Population } \\
08 \\
09 \\
13 \\
14 \\
15\end{array}$} & \multirow[b]{2}{*}{$\begin{array}{c}\text { Number } \\
\text { of Bs } \\
\text { per plant } \\
0-8 \\
0-3 \\
0-2 \\
0 \\
0-3\end{array}$} & \multicolumn{3}{|c|}{$\begin{array}{l}\text { Sample in } \\
\text { experimental field }\end{array}$} & \multicolumn{3}{|c|}{ Sample in original site } & \multicolumn{2}{|c|}{ Additional plants } & \multirow[b]{2}{*}{$\begin{array}{c}\begin{array}{c}\text { Total } \\
\text { plants } \\
\text { examined }\end{array} \\
50 \\
93 \\
36 \\
33 \\
48\end{array}$} & \multirow[b]{2}{*}{$\begin{array}{l}\quad \text { Morphology } \\
\text { Mostly ligustica } \\
\text { Speltoides } \\
\text { Mostly speltoides } \\
\text { Mostly ligustica } \\
\text { Mostly speltoides }\end{array}$} \\
\hline & & $\begin{array}{c}\text { Total } \\
45 \\
59 \\
36 \\
33 \\
48\end{array}$ & $\begin{array}{c}\text { B-carriers } \\
38 \\
17 \\
9 \\
0 \\
11\end{array}$ & $\begin{array}{r}\% \\
84 \cdot 4 \\
28 \cdot 8 \\
25 \cdot 0 \\
0 \cdot 0 \\
22 \cdot 9\end{array}$ & $\begin{array}{l}\text { Total } \\
\frac{28}{-} \\
-\end{array}$ & $\begin{array}{c}\text { B-carriers } \\
\frac{4}{-} \\
=\end{array}$ & $\frac{\frac{\%}{14 \cdot 2}}{=}$ & $\begin{array}{c}\text { Total } \\
5 \\
6 \\
- \\
- \\
-\end{array}$ & $\begin{array}{c}\text { B.carriers } \\
4 \\
3 \\
= \\
=\end{array}$ & & \\
\hline
\end{tabular}

The method of PMG collection and fixation and the routine of the cytological examination are given elsewhere (Zarchi et al., 1972). The full cytological examination was given to all plants included in table 1 . For each plant, chiasmata were scored in 10 cells at early metaphase I. Chiasmata were regarded as terminal when the chromosome arms beyond them could not be observed. Other chiasmata were regarded as interstitial.

\section{RESULTS}

\section{(i) Frequency of $B$-carriers in natural populations}

Table 1 contains new data for populations 08 and 09 on which we reported previously (Simchen et al., 1971) as well as data on three new populations from Turkey. Two of the latter, populations 13 and 15, show approximately a quarter of the plants to carry supernumerary chromosomes, from 1 to 3 per plant. These chromosomes behave similarly to the $B$ chromosomes found in populations 08 and 09 (Simchen et al., 1971). The sample from population 14 does not contain B chromosomes.

The samples collected from the two Israeli populations in 1970 showed more than a two-fold increase in the frequency of B-carriers relative to our 1969 samples: from 40 to 84 per cent in population 08 and from 12 to 29 per cent in population 09 (compare table 1 with Simchen et al., 1971). We have an additional sample from population 09, namely of plants growing in the original site in 1971, which shows a reduced frequency of B-carriers15 per cent. Presumably, the latter plants developed from the same batch of seed as our sample that was grown in the experimental field. The difference between these two samples (given in table 1) may have resulted from natural selection acting differently on B-carriers and non-carriers (see next section and the Discussion). 
It should also be mentioned that plants with very high numbers of $B$ chromosomes were found in populations 08: 5 plants with 4 Bs each, 6 plants with $5 \mathrm{Bs}, 4$ plants with $6 \mathrm{Bs}$, one with 7 and one with 8 supernumerary chromosomes. Sibs (plants originating from the same spike) showed a high correlation for the presence of B chromosomes, as found previously (Simchen et al., 1971) and expected from the accumulation mechanism demonstrated by Mendelson and Zohary (1972).

\section{(ii) Vigour of plants with and without $B$ chromosomes}

It is difficult to assess a quantitative character such as vigour, unless the plants are grown in a randomised and well-controlled experiment. This was the case with our plants. We have attempted to classify all the plants of populations 08 according to one of three categories of vigour: (1) welldeveloped plants, with numerous tillers (over 100): (2) medium-developed plants (10-100 tillers): (3) poorly developed plants, with few short tillers and small spikes. It should be noted that our field conditions, particularly the spacing between plants, were clearly much superior to those usually encountered in the wild, but we believe that the scores obtained under these conditions reflect the true developmental potential of the plants. Table 2 consists of the classification of the plants of population 08 according to vigour and the number of $\mathrm{B}$ chromosomes they contain. In addition to the 50 plants shown in table 1 , table 2 also includes 13 plants that were grown in the same randomised experimental plot and were progeny of plants from

TABLE 2

Vigour of plants of population 08 origin

\begin{tabular}{cccc}
$\begin{array}{c}\text { Number } \\
\text { of Bs } \\
\text { per plant }\end{array}$ & \multicolumn{3}{c}{ Plant development } \\
\cline { 2 - 4 } 0 & 6 & 6 & Medium \\
$1-2$ & 9 & 11 & 1 \\
$3-4$ & 4 & 13 & 0 \\
$5-6$ & 0 & 7 & 5 \\
$7-8$ & 0 & 0 & 2
\end{tabular}

Note: This table includes also 13 plants, not included in table 1 , which were grown in the same experimental field.

population 08 (the latter plants were not included in the chiasma analysis that follows). It is clear from table 2 that plants carrying high numbers of $\mathrm{Bs}$ are less vigorous than plants with fewer Bs.

\section{(iii) Chiasmata and supernumerary chromosomes}

In an earlier study (Zarchi et al., 1972) we have analysed the frequencies of interstitial and total chiasmata in five populations of $T$. speltoides. A number of control experiments were performed and environmental effects were assessed. In the present study we were particularly interested in the possible connections between the presence (and number) of B chromosomes and the frequency and distribution of chiasmata in the regular set of chromosomes (the A chromosomes). The data were evaluated in light of our previous study (Zarchi et al., 1972), which included various controls, but the detailed family analysis has been omitted from the present report. 
Table 3 demonstrates that there is little or no difference between Bcarriers and plants without Bs with respect to chiasma frequencies (and distribution) in the two Turkish populations. In the two Israeli populations, on the other hand, although the total number of chiasmata does not differ between plants with and without Bs, the B-carriers show a higher number of interstitial chiasmata and a lower number of terminal chiasmata. Withinplant variances of chiasma frequencies did not differ when plants with and without Bs were similarly compared, and these figures were not included in table 3.

TABLE 3

Comparison of means of chiasmata in plants with and without Bs in four populations

\begin{tabular}{|c|c|c|c|c|c|c|c|c|c|c|c|}
\hline \multirow{2}{*}{$\begin{array}{l}\text { Origin and } \\
\text { population }\end{array}$} & \multicolumn{2}{|c|}{$\begin{array}{l}\text { Number } \\
\text { of plants }\end{array}$} & \multicolumn{3}{|c|}{ Total chiasmata } & \multicolumn{3}{|c|}{$\begin{array}{l}\text { Interstititial } \\
\text { chiasmata }\end{array}$} & \multicolumn{3}{|c|}{ Terminal chiasmata } \\
\hline & $-\mathrm{Bs}$ & $\overrightarrow{+B s}$ & $-B s$ & + & $\mathbf{F}$ & $-\mathrm{Bs}$ & $+\mathrm{Bs}$ & $\mathbf{F}$ & $-\mathrm{Bs}$ & $+B s$ & $\mathbf{F}$ \\
\hline rael: $\quad 08$ & 8 & 42 & & & $<$ & & $2 \cdot 70$ & & $12 \cdot 59$ & $10 \cdot 63$ & $10 \cdot 0 *$ \\
\hline 09 & 69 & 24 & 4 & 13 . & $<1$ & $0 \cdot 44$ & $1 \cdot 66$ & $68.9 * * *$ & $13 \cdot 10$ & $11 \cdot 61$ & $36 \cdot 8 * * *$ \\
\hline urkey: 13 & 27 & $\begin{array}{r}9 \\
10\end{array}$ & $\begin{array}{l}13 \cdot 57 \\
13 \cdot 85\end{array}$ & $13 \cdot 19$ & $\begin{array}{c}4 \cdot 1^{*} \\
<1\end{array}$ & $0 \cdot 76$ & $0 \cdot 63$ & $\begin{array}{l}<1 \\
<1\end{array}$ & $12 \cdot 81$ & $12 \cdot 56$ & $<1$ \\
\hline 15 & 36 & 10 & $13 \cdot 85$ & 13.98 & $<1$ & 1.95 & $2 \cdot 37$ & $<1$ & 11.90 & $11 \cdot 61$ & $<1$ \\
\hline
\end{tabular}

$\mathrm{F}$ denotes the variance ratio in analysis of variance, in which the variance between the two groups is compared with the variance between plants within groups. * Significance level $0 \cdot 05-0 \cdot 01 ; * * *$ significance level less than $0 \cdot 001$.

To test further the relation between supernumerary chromosomes and chiasma distribution, we analysed the regression of interstitial and terminal chiasmata on the number of Bs, as shown in figs. 1 and 2 for populations 08 and 09, respectively. As expected, populations 13 and 15 did not have coefficients of regression and correlation significantly different from zero. Several points emerge from these analyses: (1) There is a positive linear regression of the frequency of interstitial chiasma on the number of $\mathrm{Bs}$ in both Israeli populations. (2) Negative linear regressions can be fitted to the relation between terminal chiasmata and the number of Bs. (3) The negative and positive slopes are quite similar to each other in each population.

(4) The regression coefficients are population-specific: the largest coefficients are found in population $09(-0.88$ and 0.71$)$, smaller ones in population $08(-0.59$ and 0.60$)$ and coefficients not significantly different from zero in populations 13 and 15 .

\section{Discussion}

Samples from eight populations of $T$. speltoides have now been examined cytologically (Simchen et al., 1971; Zarchi et al., 1972 and the present study), four of which contained high proportions of plants with supernumerary chromosomes. Why are these chromosomes common in some populations and rare or absent in others? Our limited number of populations does not suggest any relation between environmental factors and the presence and frequency of $\mathrm{Bs}$, nor between the latter and the other polymorphism for which this species is noted, namely the ligustica-speltoides fruit morphs (Zohary and Imber, 1963). In fact, population 08, in which most individuals carry B chromosomes, and population 14, where none was found, share many ecological characteristics, and both consist mostly of ligustica plants. 


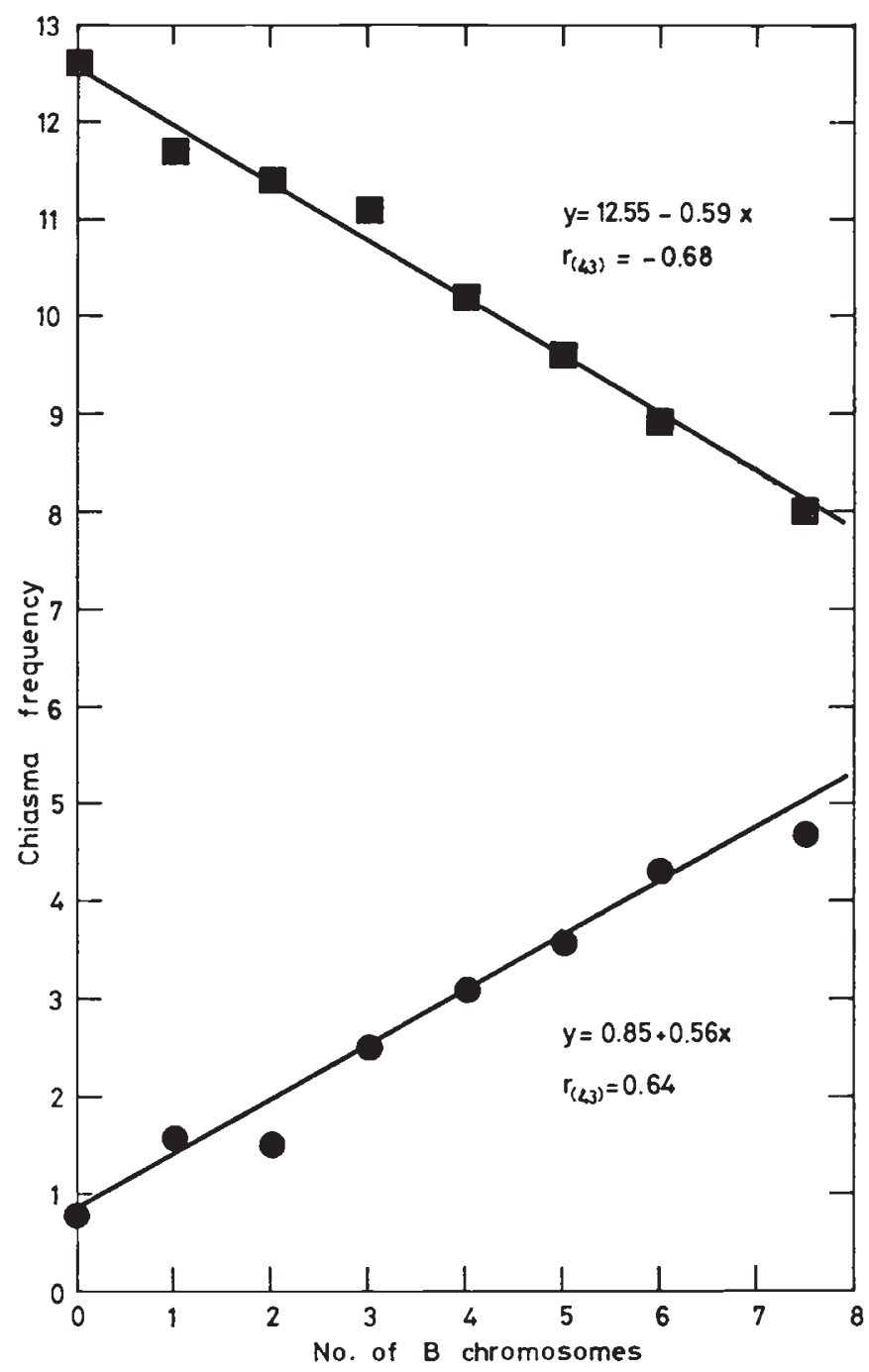

Fig. 1.-The relationship between chiasma frequency and the number of $\mathrm{B}$ chromosomes per plant in population 08. Means of terminal $(\square)$ and interstitial $(\circlearrowleft)$ chiasmata were calculated for the plants sharing the same number of Bs. The single plants with 7 and $8 \mathrm{~B}$ chromosomes were grouped together. The regression lines were calculated from individual values of 45 plants and are both highly significant $(P<0 \cdot 001)$.

In the two Israeli populations, 08 and 09, we observe marked differences in frequencies between our previous and the present samples (seed collected in 1969 and 1970, respectively). These might reflect the environmental differences between the 2 years and the fact that under some conditions B-carriers have a different average fitness value than plants without Bs. The lower frequency of B-carriers reported here (table 1) for the Haifa sample (population 09), in which PMC were obtained from the wild, also supports such differences in fitness, and even suggests that in the 1970/71 Haifa conditions, B-carriers were selected against. 




FIg. 2.-The relationship between chiasma frequency and the number of $\mathrm{B}$ chromosomes per plant in population 09. This figure is comparable with fig. 1 , but note the change of scale on the abscissa. The regression lines were calculated from individual values of 87 plants and are both highly significant $(P<0.001)$.

The assessment of plant vigour (table 2) clearly supports the view that B-carriers, particularly plants carrying high numbers of B chromosomes, are selected against. Mendelson and Zohary (1972) have found that Bcarriers that were derived from our populations 08 and 09 showed marked pollen abortion (up to $40-50$ per cent abortion in plants carrying $6 \mathrm{Bs}$ ). Selection against individuals carrying a large number of $\mathrm{B}$ chromosomes, expressed as reduced seed-set, was observed in rye by Muntzing (1943) and by Jones and Rees (1967). Such plants also showed reduced height and 
delayed flowering (Jones and Rees, 1968). Reduced seed-set and pollen abortion were also found in Lilium callosum carrying supernumerary chromosomes (Kayano, 1962).

To balance out the reduced fitness of plants with $\mathrm{B}$ chromosomes, one can observe the existence of accumulation mechanisms during the male and female gametogenesis and later, the net result of which is that there is a positive preferential transmission of Bs to progeny. This was found in T. speltoides (Mendelson and Zohary, 1972) as well as in other organisms.

In population 08 we observed 17 plants with 4-8 supernumerary chromosomes. Such high numbers were not observed in the other populations and might not be tolerated but in population 08 . We observe also that Mendelson and Zohary (1972), who raised plants from seed obtained from us by open pollination of three plants \#1450, \# 168, \#1601 (Simchen et al., 1971), found high numbers of Bs only among the progeny of \# 1450 (mistakenly reported by Mendelson and Zohary as \# 145). This latter plant originated from population 08 and contained $3 \mathrm{Bs}$, while the other two plants originated from population 09 (and contained $2 \mathrm{Bs}$ each- see table 2 of Simchen et al., 1971).

We feel that our most significant findings concern the distribution of chiasmata. Earlier, our preliminary data indicated that the mean chiasma number is reduced in B-carriers compared with non-carriers of the same population (Simchen et al., 1971; Zarchi et al., 1972). The present, much more extensive data, show that this is not the case in three out of four populations (table 3). However, in the two Israeli populations, terminal chiasmata are reduced and interstitial chiasmata are increased in B-carriers in an almost compensatory way, as if only the location of chiasmata in bivalents is changed. This effect is even more striking when one observes how similar the positive and negative slopes (for interstitial and terminal chiasmata, respectively) are in fig. 1 and 2 . One can speculate on the causal relationship between the $\mathrm{B}$ chromosomes and this distributionary effect, but no clear indications are available. One possibility is a direct genetic control on chiasma distribution exercised by the $\mathrm{B}$ chromosome. Another group of possibilities is that they change the time-table of meiosis in a way that pairing and/or chiasma terminalisation are not completed. We know little about terminalisation in $T$. speltoides, but it is not very extensive from diakinesis onwards (Zarchi et al., 1972). Another possibility, which would explain the linear relationship between the number of Bs and the distribution effect, is that the supernumerary chromosomes compete with the regular set for substances required for the latters' pairing, exchange or terminalisation. It should be remembered, however, that associations between Bs are probably not chiasmatic, as rings of $3 \mathrm{Bs}$ were found (Simchen et al., 1971). It should also be noted that the above possibilities are not meant to be mutually exclusive, and any of several combinations could, upon further research, turn out to be close to the truth.

One additional point emerges from our data, namely that the distribution effect is population specific. It does not appear in the two Turkish populations, and differs quantitatively between the two Israeli populations (compare the slopes in figs. 1 and 2). Thus the effect, whether causal or correlative, depends largely on the genetic make-up of the plants, and not only on the presence of $\mathrm{B}$ chromosomes. 


\section{References}

JONES, R. N., AND REES, H. 1967. Genotypic control of chromosome behaviour in rye. XI. The influence of B chromosomes on meiosis. Heredity, 22, 333-347.

JONES, R. N., AND REES, H. 1968. The influence of B chromosomes upon nuclear phenotype in rye. Chromosoma, 24, 158-176.

KAYANo, H. 1962. Cytogenetic studies in Lilium callosum. V. Supernumerary B chromosomes in wild populations. Evolution, 16, 246-253.

MENDELSON, D., AND ZOHARY D. 1972. Behaviour and transmission of supernumerary chromosomes in Aegilops speltoides. Heredity, 29, 329-339.

MUNTZING, A. 1943. Genetical effects of a duplicated fragment chromosome in rye. Hereditas, 29, 91-112.

SIMCHEN, G., ZARCHI, Y., AND HILLEL, J. 1971. Supernumerary chromosomes in the second outbreeding species of the wheat group. Chromosoma, 33, 63-69.

ZARGHI, Y., SIMCHEN, G., HILLEL, J., AND SCHAAP, T. 1972. Chiasmata and the breeding system in wild populations of diploid wheats. Chromosoma, 38, 77-94.

zOHARY, D., AND IMBER, D. 1963. Genetic dimorphism in fruit-types in Aegilops speltoides. Heredity, 18, 223-231. 